\title{
Effect of Plasma Arc Welding on Residual Stress and Distortion of Thin Titanium Sheet
}

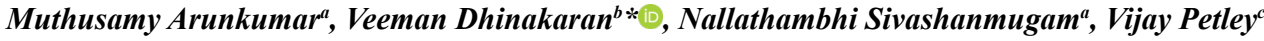 \\ ${ }^{a}$ National Institute of Technology, 620 015, Tiruchirappalli, Tamil Nadu, India \\ ${ }^{b}$ Chennai Institute of Technology, Kundrathur, 620 069, Chennai, Tamil Nadu, India \\ ${ }^{c}$ Gas Turbine and Research Establishment, DRDO, 560093, Bangaluru, Karnataka, India
}

Received: June 4, 2019; Revised: October 29, 2019; Accepted: November 10, 2019

\begin{abstract}
In this research work, a finite element model is developed to predict the temperature field and residual stress during plasma arc welding of thin Ti-6Al-4V sheets. Dhinakaran's heat source model which is based on Parabolic Gaussian distribution is used to predict the temperature field and Anand's model is used to predict the residual stress. Numerical simulation is performed using ANSYS ${ }^{\circledR}$. Heat transfer analysis is carried out primarily and the temperature field is given as the input for structural analysis. The concept of APDL programming is used to implement the governing equations. Experimental work has also been conducted to validate the predicted data. Hole Drilling Method (HDM), a semi destructive method and XRD analysis is used to measure the residual stress on the welded specimen. A good agreement is found between the predicted values and measured values.
\end{abstract}

Keywords: Dhinakaran's model, Ti-6Al-4V, residual stress, Hole Drilling method, XRD analysis.

\section{Introduction}

Titanium has widespread application in the fields of aerospace, biomedical and automobiles due to their unique properties such as exceptional strength-to-weight ratio, and corrosion resistance ${ }^{1,2}$.

Among the various titanium alloy, Ti-6Al-4V is considered as workhorse due its high practice and also it can be welded by variety of processes. Tungsten Inert Gas Welding (TIG), Laser Beam Welding (LBW), friction welding, Electron Beam Welding (EBW), and Plasma Arc Welding (PAW) are the most widely used one ${ }^{1-3}$. Although there are various processes used for joining titanium and its alloys, PAW is preferred candidate to yield high quality welds, high depth to width ratio at better welding rate ${ }^{4}$. In addition, the capital cost is lower than LBW and EBW ${ }^{5}$.

During the course of welding thin materials, a weldment is locally heated by a moving heat source ${ }^{6}$ and the fusion zone and heat affected zone (HAZ) are subjected to a higher temperature than that of base metal.

High localized heat transfer and strong non-uniform temperature field during the heating and cooling cycles makes non-uniform thermal expansion and contraction which results in inhomogeneous plastic deformation in the weld metal and its surrounding. This leads to formation of residual tensile and compressive stresses in the work piece due to the uneven heating and cooling ${ }^{7-9}$. The presence of tensile residual stress is the cause for reduction in fatigue strength and further compressive residual stress will diminish the stability limit of the material ${ }^{10,11}$. Hence it is a prerequisite to estimate the magnitude of the welding stress and distortion, to avoid the undesired happenings.
Due to the availability of modern computational techniques, finite element method (FEM) is used as one of the effective tool for predicting the residual stresses and distortion. However, prediction of residual stress will be complicated when phenomena like melting, evaporation, absorption, keyhole forming and plasma forming ${ }^{12}$. A three dimensional cone shaped volumetric heat source for thermal analysis are considered the material as thermo elastic plastic with rate independent plasticity for mechanical analysis is used to analyze the residual stress on laser beam welding of Ti-6Al-4V alloy. The predicted results are in good agreement with experimental result obtained by hole-drilling method ${ }^{13}$. A3D Finite Element Model (FEM) model was used to predict the temperature distribution and residual stress distribution during autogenously laser welding of high strength steel by Wei et al. The formation plastic strain is predicted using von Mises yield criterion ${ }^{14}$.

A thermal elastic plastic finite element model was developed to predict the residual stress of Variable polarity plasma arc welded aluminum ${ }^{15}$. Hole drilling method was used to measure the residual stress experimentally and showed good agreement with the predicted result ${ }^{16}$. A 3D finite element model was formulated using double ellipsoidal heat source to predict the temperature field of GTA welded modified 9Cr-1Mo steel. The predicted temperature distribution and residual stress were compared with thermocouple reading and XRD measurement. A good agreement was seen among the results ${ }^{17}$. A 3D finite element model was developed to analyse the residual stress in friction stir welded 304 steel plate. Neutron diffraction method was used to measure the residual stress experimentally and showed good agreement with predicted values ${ }^{18}$. 
Based on the literature review, it is inferred that most of the work on residual stress simulation have been carried out on friction stir welded material. Limited number of work have been carried out in predicting the residual stress of high energy density welding process like LBW, EBW and PAW materials. Hence an effort is made to measure the residual stress of plasma arc welded Ti-6Al-4V alloy using Hole Drilling Method, X-ray Diffraction method and compare these experimental values with predicted values results from simulation. Thermo-mechanical simulation is carried out using COMSOL code. Heat transfer analysis is carried out using new three dimensional volumetric heat source (Dhinakaran's model) to predict the temperature distribution and structural analysis is carried out using Anand constitutive model to predict the residual stress ${ }^{19,20}$.

\section{Experimental Work}

The plasma arc welding experiment is conducted using Fronius magic wave 4000 machine. Two Ti-6Al-4V plates of $185 \times 100 \times 2 \mathrm{~mm}$ dimension is used to obtain butt weld joint. The chemical properties of Ti-6Al-4V material is presented in Table 1.

Table 1. Chemical compositions of Ti-6Al-4V.

\begin{tabular}{lccccccc}
\hline Component & $\mathrm{Ti}$ & $\mathrm{Al}$ & $\mathrm{Fe}$ & $\mathrm{O}$ & $\mathrm{V}$ & $\mathrm{Mn}$ & $\mathrm{Nb}$ \\
\hline Weight in $\%$ & 89.51 & 6 & 0.25 & 0.2 & 4 & 0.009 & 0.022 \\
\hline
\end{tabular}

The material is cleaned to eliminate the oxide layers and contaminations before welding. Large number of experimental trials are conducted in order to find out the influencing parameter for welding of TI-6Al-4V alloy. Finally, three parameters namely welding current, travel speed and stick off distance are chosen for conducting bead on plate welding trials. Table 2 shows the experimental setup conditions. It is found that a stick off distance of $8 \mathrm{~mm}$ is very useful in achieving better fusion and decided to keep it as constant parameter. Totally 9 bead on plate experimental trials have been conducted. In order to move and control the welding torch precisely a CNC work table is used. Since titanium alloy has great affinity with oxygen, nitrogen at elevated temperature, a special trailing shield is used to protect the molten pool. Argon with $99.9 \%$ purity is used as the shielding and trailing gas.

Since Ti-6Al-4V has low thermal conductivity $(7 \mathrm{~W} / \mathrm{mK})$, the heat produced by the process should not alter the structure of the material during cutting process. The usage of wire EDM prevents the local heating of Ti-6Al-4V during cut. The standard specimens are cut for macro examination to investigate weld bead geometry. From macro examination welding current of $60 \mathrm{~A}, 250 \mathrm{~mm} / \mathrm{min}$ travel speed and $8 \mathrm{~mm}$ stick off distance is found to be the optimized parameter to get full depth of penetration.
Table 2. PAW experimental set up conditions.

\begin{tabular}{ll}
\hline Power source & Fronius magic wave 4000 \\
\hline Polarity & DCEN \\
Electrode & $2 \%$ Thoriated tungsten electrode \\
Electrode diameter & $1 \mathrm{~mm}$ \\
Plasma gas & Argon \\
Plasma gas flow rate & $1.5 \mathrm{LPM}$ \\
Shielding gas & Argon \\
Shielding gas flow rate & $12 \mathrm{LPM}$ \\
Trailing shield gas flow rate & $20 \mathrm{LPM}$ \\
Nozzle to plate distance & $8 \mathrm{~mm}$ \\
Nozzle orifice diameter & $2.8 \mathrm{~mm}$ \\
Torch position & Vertical \\
Operation type & Automatic \\
\hline
\end{tabular}

The parameter used for the welding process to obtain a butt joint are given in Table 3. Required number of butt joint specimens have been prepared in order to investigate its mechanical property and integrity of the weld. The deformation of the butt joined is seen in the Figure 1.

Table 3. Weld input parameters.

\begin{tabular}{ll}
\hline Current(A) & 60 \\
\hline Voltage(V) & 20.8 \\
Travel Speed & $250 \mathrm{~mm} / \mathrm{min}$ \\
Arc Length & $8 \mathrm{~mm}$ \\
\hline
\end{tabular}

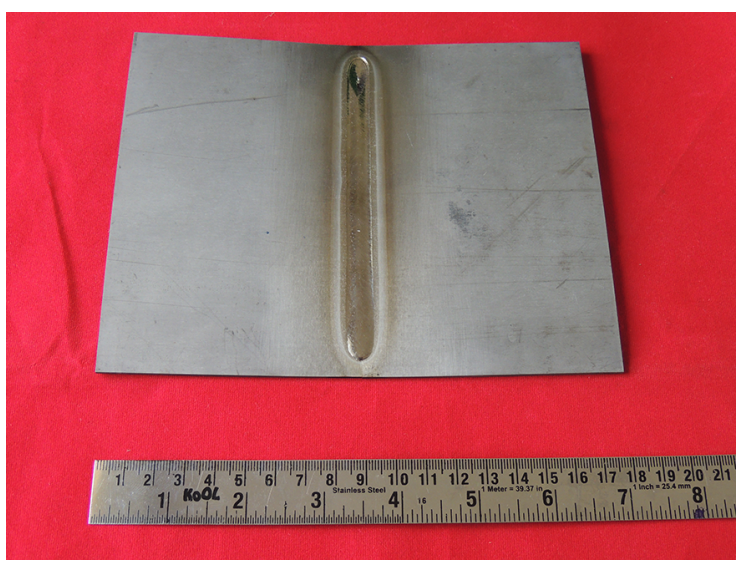

Figure 1. Deformation of thin sheets after welding.

\subsection{Hole drilling method}

Hole drilling method (HDM) is employed to measure the residual stress along transverse and longitudinal direction on the butt welded plate. It is one of the important technique to measure the residual stress because the damage caused by this method will not affect the usefulness of the material ${ }^{21-23}$. 
This method also is known as semi destructive method ${ }^{24}$. In this research, the experiment is carried out at Structural Engineering Research Centre, Council of Scientific \& Industrial Research (CSIR), Chennai. The test is conducted as per American Society for Testing and Materials (ASTM) standard E837-0125,26.

The butt welded pate in which the stress has to be measured is cleaned gently with acetone in order to remove the foreign particles. A strain gauge rosettes with three elements are fixed on the respective area along the transverse and longitudinal direction as shown in Figure 2. The reason for using three element rosette is that the stresses are biaxial stress. The standard manufacturer instructions are followed to cement the strain rosettes and lead wires of the strain rosette is wired and attached to a multichannel stress strain indicator. The geometric center of the strain rosette is located with the help of alignment set up, a precision milling guide which has the microscope and eyepiece. A hole is made through the geometric center of the strain rosette in the material for the depth of $0.254 \mathrm{~mm}$ before which the gauge circuit is zero balanced. The drilling is done with the help of high speed air turbine using carbide cutter. A large scaled micrometer is located around the drill barrel which is operated manually to control the drill depth. A series of hole are drilled about five times with the drilling depth of $0.254 \mathrm{~mm}$. Due to the drilled hole, the residual stress is relieved as deformation relative to the change in stress around the hole which is measured by the bonded strain rosette. The strain values are printed from the multichannel strain indicator and they are used to find out the residual stress. The minimum principal stress, maximum principal stress and orientation of principle stress are calculated from the following expression according to linear elastic principle (as per standard E837-01).

$$
\begin{gathered}
\sigma_{\max }=\frac{\varepsilon_{1}+\varepsilon_{3} .}{4 A}-\frac{1}{4 B} \sqrt{\left(\varepsilon_{3}-\varepsilon_{1}\right)^{2}+\left(\varepsilon_{3}+\varepsilon_{1}-2 \varepsilon_{2}\right)^{2}} \\
\sigma_{\min }=\frac{\varepsilon_{1}+\varepsilon_{3} .}{4 A}+\frac{1}{4 B} \sqrt{\left(\varepsilon_{3}-\varepsilon_{1}\right)^{2}+\left(\varepsilon_{3}+\varepsilon_{1}-2 \varepsilon_{2}\right)^{2}} \\
\tan 2 \alpha=\frac{\varepsilon_{1}-2 \varepsilon_{2}++\varepsilon_{3}}{\varepsilon_{1}-\varepsilon_{3}}
\end{gathered}
$$

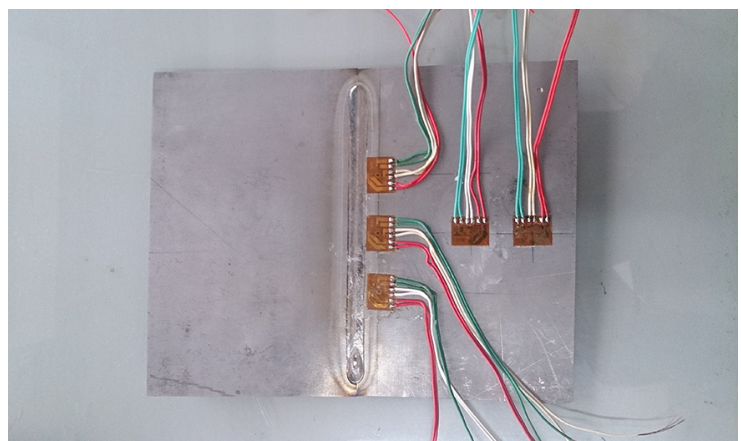

Figure 2. Positions of strain gauges on the thin sheets.
The value of A, B are constant which incorporate the elastic behavior of material as well as severely reflects the attenuation of relieved strain with respect to the relaxed stress. These values are calculated using the following expression.

$$
\begin{gathered}
A=-\frac{a(1+\mu)}{2 E} \\
B=-\frac{b}{2 E}
\end{gathered}
$$

The value of $\mathrm{a}, \mathrm{b}$ are dimensionless constants and taken from the ASTM E -837 standards of Table 1. The ratio of Diameter of hole $\left(D_{0}\right)$ to diameter gage $(D)$ gives the value of constant " $a$ " and the ratio of depth of hole (Z) to diameter of gage (D) give the value of constant" b".

\section{$2.2 X$-ray Diffraction testing equipment}

XRD method, a type of nondestructive method, is also used to measure the residual stress in the welded plate. XRD measurement is conducted at Gas Turbine Research Establishment, Bangalore.

The StressTech X 3000 XRD machine which is the made in Finland is used for conducting experiment. The machine is controlled by a computer and has the capability to store the data, processing the data and displaying the data. Figure 3 shows the XRD residual stress measurement set up.

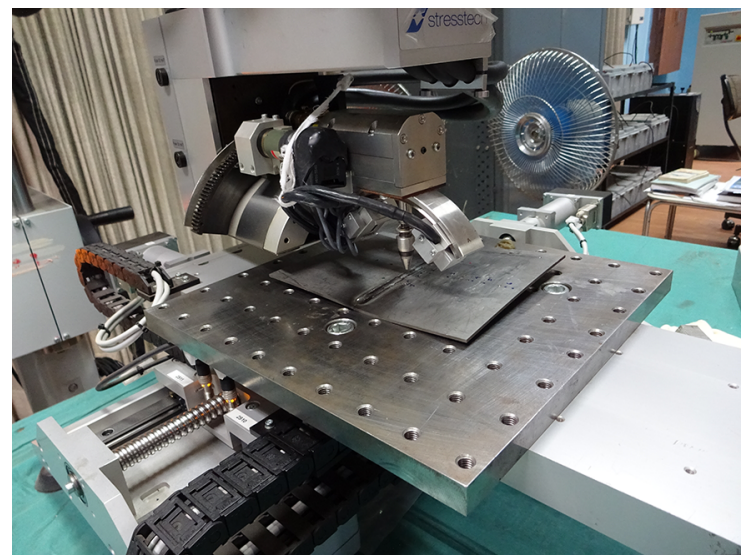

Figure 3. Residual Stress measurement $-\mathrm{XRD}$.

Selection of suitable tube is the important characteristics which should be done on the basis of wavelength target material and intensity on the specimen to be tested. The XRD testing equipment has been calibrated with standard titanium specimen. Titanium tube is carefully replaced and used as the source for the generation of X-ray. The measurement parameter used for conducting the experiment are given in the Table 4. 
Table 4. Measurement Parameters.

\begin{tabular}{ll}
\hline Exposure Time & 40 Seconds \\
\hline No. of Inclination & 4 on either side \\
Psi oscillation & 1 Degree \\
Inclination & 40 Degree \\
Current & $6.58 \mathrm{~mA}$ \\
Voltage & $30 \mathrm{kV}$ \\
No. of Detectors & 2 \\
\hline
\end{tabular}

XRD method works on the basis of Bragg's law proposed by W.L. Bragg. The inter planer spacing between atom of any material is altered when temperature load or force is applied on it. The change in distance between the crystallographic planes is used as strain to calculate the residual stress ${ }^{27}$. Increase in lattice spacing value compared to the stress free value indicates that tensile stress is formed and decrease in lattice spacing value indicates that compressive stress is formed. When a monochromatic beam of X-rays with particular wavelength is passed through the 3-D array of atoms, each atomic plane reflects the incident beam. The diffraction angle $(2 \theta)$ is measured experimentally and the inter planer spacing is measured from the Bragg's law and it is given by.

$$
2 d \sin \theta=\mathrm{n} \lambda
$$

Where $\mathrm{n}$ represents order of diffraction (an integer), $\mathrm{d}$ represents the inter planer spacing between the crystals, $\lambda$ represents the wavelength and $\theta$ represents the angle of diffraction.

\subsection{Distortion Measurement}

Due to alternate heating and cooling cycles during welding, non-uniform thermal stresses are induced in the component. If the induced stresses exceed the yield strength of the base metal, the metal undergoes localized plastic deformation. Plastic deformation causes a permanent change in dimensions of the component and finally, distorts the component. Distortion occurred because of these welding residual stresses (RS) is particularly problematic for the assembly of thin structures and often requires costly reworking. To understand the influence of process parameters on RS and distortion, RS measurements have been made in $2 \mathrm{~mm}$ thick butt-welded Ti-6Al-4V plate. Distortion of titanium alloy sheet before and after welding is measured using Coordinate Measuring Machine (CMM) at marked grid line as depicted in Figure 4. CMM has six degrees of freedom. A probe which is attached to third moving axis of the machine defines the measurement. The CMM used for the measurement is WIZ probe, a product of NEXTEC Technologies, Israel.

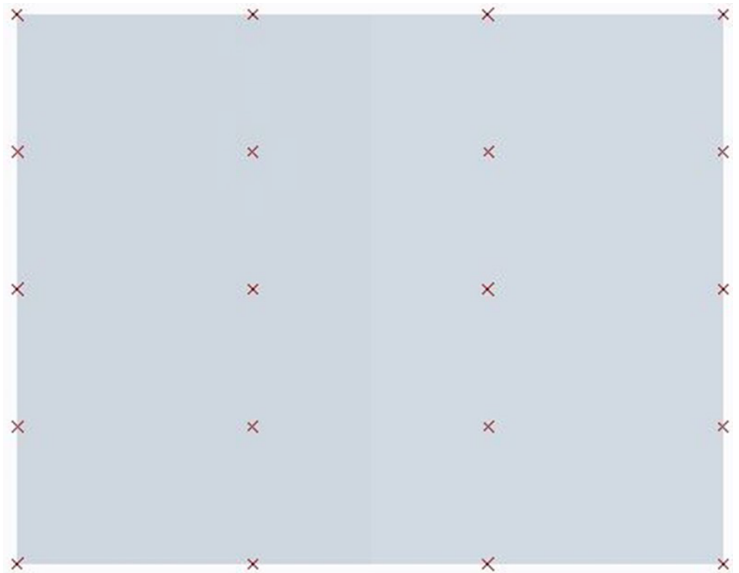

Figure 4. Nodes selected for distortion measurement.

The butt-welded specimen seems to have angular distortion. Figure 4 shows schematic representation of the selected nodes on the sheet before welding. One of the corner of the plate is chosen as the reference point. Totally, 20 nodes are selected. The coordinates of each node is noted by focusing the laser light on the node and receives a reflected signal. The orientation of the sensor remains fixed during the measurement. The measurement which are measured on normal thin sheet stands as the reference value at the nodes. When the laser beam is focused on the distorted plate, the distance to the distorted surface is measured. The measurement system has a data acquisition system which stores the values at each nodes during the measurement of normal sheet and welded sheet. The CMM set up is shown in Figure 5.

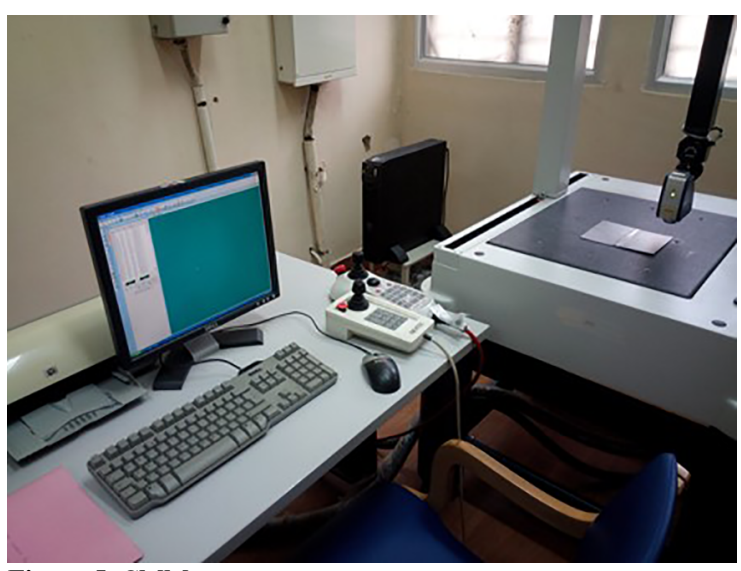

Figure 5. CMM measurement.

\section{Numerical Modelling}

Numerical modelling is a best alternate method for any costly experimental trials ${ }^{28}$ and hence use of numerical modelling will be better option for Ti-6Al-4V. Three essentials steps have to be followed to model a welding problem. 
A mathematical equation which defines the physical arc behavior of PAW needs to be selected if already existing or new heat source model has to be developed. Dhinakaran et al. has used Dhinakaran's model to simulate the process of PAW process. Secondly a commercial finite element method is chosen to solve the governing equation of the physical problem. Thirdly the predicted results from the finite element simulation is ensured by validating with the experimental result.

\subsection{Heat Source Model}

According to macro examination, heat intensity distribution is observed to be decay in parabolic manner in plasma arc welded thin sheets of Ti-6Al-4V alloy. Hence, a newly developed (Dhinakaran's model) heat source was used to predict the temperature distribution.

The heat intensity distribution at any plane normal to the $\mathrm{z}$ direction is represented as

$$
Q(r, z)=Q_{0} \exp \left(-\frac{3 r^{2}}{r_{0}^{2}}\right)
$$

The distribution parameters are represented as

$$
r_{0}(z)=a z^{2}+b
$$

The maximum heat intensity is given as

$$
Q_{0}=\frac{3 \eta V I e^{3}}{A_{v} \pi\left(e^{3}-1\right)}
$$

where $A_{v}=a^{2}\left(z_{i}^{4} H+2 z_{i}^{2} H^{3}+2 z_{i}^{3} H^{2}+z_{i} H^{4}+\frac{H^{5}}{5}\right)$ $+2 a b\left(z_{i}^{2} H+z_{i} H^{2}+\frac{H^{3}}{3}\right)+b^{2} H$

The efficiency of welding is considered as 0.53 .

\subsection{Governing Equation and Boundary conditions}

Principle of conservation of energy is followed in any welding process. A 3D nonlinear transient heat conduction is stated as

$$
\begin{gathered}
p c \frac{\partial T}{\partial t}=\frac{\partial}{\partial x}\left(k \frac{\partial T}{\partial x}\right)+\frac{\partial}{\partial y}\left(k \frac{\partial T}{\partial y}\right) \\
+\frac{\partial}{\partial z}\left(k \frac{\partial T}{\partial z}\right)+Q v(x, y, z)
\end{gathered}
$$

where $\mathrm{k}$ refers to thermal conductivity of material in $\mathrm{W} / \mathrm{m} . \mathrm{K}, \rho$ refers to material density in $\mathrm{kg} / \mathrm{m}^{3}$, c refers to specific heat in $\mathrm{J} / \mathrm{kg}$ $\mathrm{K}, \mathrm{QV}(x, y, z)$ refers to intensity of heat source, $v$ refers to the speed of plasma arc heat source is moving on the plate in $\mathrm{m} / \mathrm{s}$.

To solve the nonlinear transient heat conduction equation, Initial and boundary conditions are essential to be specified. When time $t=0$, the initial temperature of the material is assumed to be at ambient temperature ${ }^{29,30}$.

$$
\mathrm{T}(\mathrm{x}, \mathrm{y}, \mathrm{z}, \mathrm{t})=\mathrm{T}_{0}(\mathrm{x}, \mathrm{y}, \mathrm{z})
$$

The heat losses from the surface of the material are considered to be due to convection and radiation.

$$
k_{n} \frac{\delta T}{\delta n}-q+\varepsilon \sigma\left(T_{0}^{4}-T^{4}\right)+h\left(T_{0}-T\right)=0
$$

where $k_{n}$ refers to the thermal conductivity of the material in $\mathrm{n}^{\text {th }}$ direction, $\varepsilon$ refers to the emissivity of the surface $[0.8$ for Ti-6Al-4V alloy], $\sigma$ refers to Steffen -Boltzmann constant $\left[5.67 \times 10-8 \mathrm{~W} / \mathrm{m}^{2} \mathrm{~K}^{4}\right], \mathrm{T}_{0}$ refers to the ambient temperature [303 K], h refers to the convective heat transfer coefficient $\left[35.63 \mathrm{~W} / \mathrm{m}^{2} \mathrm{~K}\right]$ and $k_{n} \frac{\delta T}{\delta n}$ refers to transport of heat due the conduction mode which is imposed on the material surface, third term and fourth term refers to the heat loss due radiation and convection respectively.

\subsection{Finite Element Analysis}

FE analysis is performed using Ansys Parametric Design Language (APDL) available in FE code ANSYS.

The computation of welding temperature field and welding residual stress is done through coupled formulation which includes two stages. At the first stage, nonlinear transient heat conduction equation is solved to obtain temperature distribution in the material as the function of time and space. Temperature dependent material properties (Figure 6) such as density, specific heat and thermal conductivity are used for heat transfer analysis.

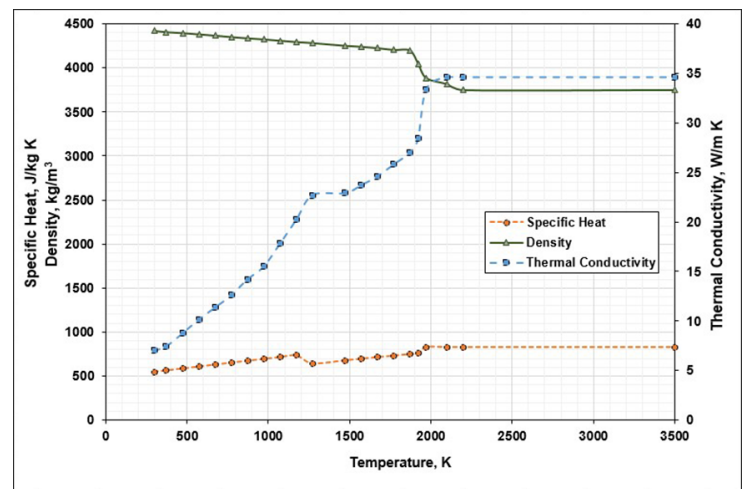

Figure 6. Temperature Dependent material properties of Ti-6Al-4V.

The properties which are used in heat transfer analysis are shown in the graph.

At the second stage, the computed temperature field is employed as thermal load to predict the residual stress in subsequent structural analysis. Temperature dependent properties like young's modules, thermal coefficient of heat expansion are used to run the structural analysis. The actual mechanical boundary condition used during experimental work has been given as boundary condition to carry out structural analysis, Solid 70 thermal filed element has been used for thermal analysis and Solid 45 element has been used for residual stress analysis. 


\subsubsection{Geometry and Mesh}

Only half of the structure is used to simulate the PAW process owing to the symmetry of the structure. Fine meshing was graded about $7 \mathrm{~cm}$ from the weld centerline in order to reflect the effect of high thermal gradient in the welding zone and there after coarse mesh was graded with increasing destine form the weld centerline.

The accuracy of the solution depends on the size of mesh. Smaller the mesh size, the accuracy of the solution will be greater and vice versa. But grading of fine meshes will take more computational time. In order to reduce the computational time and enhance the accuracy of the solution, test of convergence has been conducted. Number of simulation trials are performed to obtain reliable solution. The solution is said to be reliable when the solution did not vary with size of mesh. The three dimensional finite element model is shown in the Figure 7.

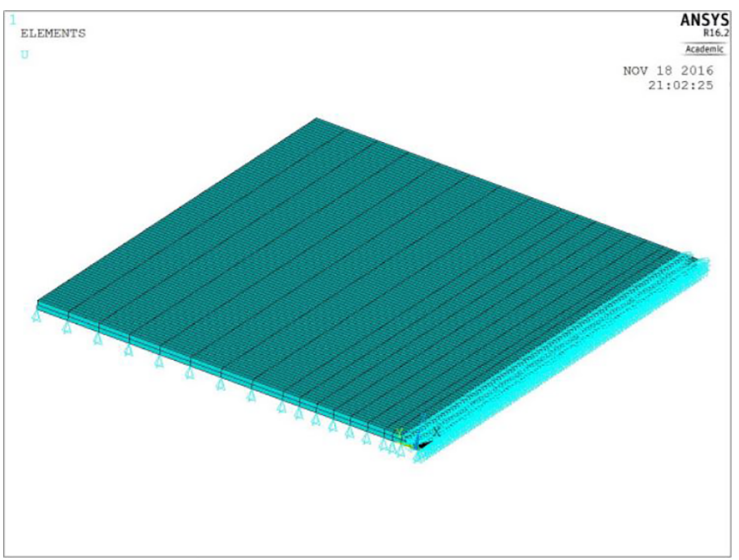

Figure 7. Three dimensional finite element model.

\subsubsection{Material model}

During welding process, the fusion zone and nearer zone of the material is subjected to high temperature. Due to this situation, response of the welded material become rate dependent and elastic viscos-plastic model will be more suitable one to represent this case. A rate dependent model known as Anand model which describes the behavior of plastic evolution during high temperature ${ }^{31,32}$.

The Anand model has two special features. First, this model does not require any loading, unloading condition and explicit yield condition. Even though plastic flow is very small at low stresses, this model assumes the plastic strain to take place at all none zero stress values. Internal state of material offers resistance to plastic flow. This internal resistance is called as isentropic resistance or deformation resistance and has the same unit of stress. The deformation resistance is denoted as single scalar variable this is the second feature of the Anand model.
The equivalent stress is directly proportional to isentropic resistance and is given by

$\sigma \alpha s$

A material parameter is introduced to equate the isentropic resistance and equivalent stress. It is realized as constant resulting from constant rate test and is found to be less than unity.

$$
\sigma=c . s \quad c<1
$$

The material parameter is defined as

$$
c=\frac{1}{\xi} \sinh ^{-1}\left[\left(\frac{\dot{\varepsilon}_{P}}{A} e^{Q / R T}\right)^{m}\right]
$$

Where $\xi$ is stress multiplier (no unit), $\varepsilon_{\mathrm{p}}$ is rate of inelastic strain, $\mathrm{A}$ is pre -exponential factor $\left(\mathrm{s}^{-1}\right), \mathrm{Q} / \mathrm{R}$ is activation energy or Boltzmann constant $(\mathrm{K}), \mathrm{T}$ is absolute temperature $(\mathrm{K}), \mathrm{m}$ is strain rate sensitivity of stress.

On substituting the value of material factor from the relation $(*)$, the equivalent stress is arrived as

$$
\begin{aligned}
& \sigma=\frac{1}{\xi} \sinh ^{-1}\left[\left(\frac{\dot{\varepsilon}_{P}}{A} e^{Q / R T}\right)^{m}\right] \cdot S \\
& \dot{\varepsilon}_{P}=A e^{(Q / R T)}\left[\sinh \left(\xi \frac{\sigma}{S}\right)\right]^{\frac{1}{m}}
\end{aligned}
$$

From the equation it is understood that the deformation resistance enters in the equation as a ratio with the equivalent stress. The equation has temperature dependence as well as stress and state dependence. The classical Arrhenius term is utilized to incorporate the temperature dependency. Garofalo proposed a steady state plastic flow model by considering hyperbolic sine function because most of the metal strain rate is not proportional to the stress exponent form at high stress region ${ }^{33-34}$. The hyperbolic function in the equation is accounting the stress and state dependency.

The evolution of the deformation resistance is assumed to follow the equation as

$$
\dot{s}=f(\sigma, s, T) \dot{\varepsilon}_{P}
$$

The function $f(\sigma, s, T)$ is associated with the strain hardening and dynamic recovery. The evolution equation was stated in simple form by Anand as follows

$$
\dot{s}=\left\{h_{0}\left(1-\frac{S}{S^{*}}\right)^{a} \cdot \sin \left[1-\frac{S}{S^{*}}\right]\right\} \cdot \dot{\varepsilon}_{P}: a>1
$$

where

$$
S^{*}=\dot{S}\left(\frac{\dot{\varepsilon}_{P}}{A} e^{Q / R T}\right)^{n}
$$


where $h_{0}$ refers to the softening/hardening coefficient, a refers to the strain rate of sensitivity of softening/hardening, $s^{*}$ refers to the saturation value of deformation resistance or internal variable for the given strain rate and temperature as indicated in the equation $(*), s$ refers to the coefficient and $\mathrm{n}$ refers to the strain rate sensitivity for the saturation value of internal variable or deformation resistance.

\section{Microstructure Examination}

Ti-6Al-4V is a binary type of alloy having BCC structured $\beta$ phase and HCP structured $\alpha$ phase. The $\beta$ phase distributes along at the boundaries of alpha phase. HCP structure is stabilized by the presence of aluminium $(6 \%)$, and BCC structure is stabilized by the presence of vanadium (4\%).

Figure 8 shows the microstructure examination of Ti6Al-4V such as base metal, HAZ and FZ. The Base metal confirms the presence of the intergranular $\beta$ phase which is black in colour and is distributed in equiaxed $\alpha$ phase which is white in colour. In welding of Ti-6Al-4V, hightemperature $\alpha$ phase is formed from primary $\beta$ phase and primary $\alpha$ phase when $\beta$ transus temperature is attained. During cooling, the high-temperature beta again transforms into martensite $\alpha$ prime. It is accomplished by diffusion or shear or both. Cooling rate is an important factor in the micro structure formation.

During welding, there is a solidification time difference between solid and liquid interface (improper mixture of solvent). This causes compositional difference which leads to a constitutional super cooling. When it solidifies below the liquidus temperature, the planer mode of solidification will break into the cellular or dendritic mode of solidification ( $\mathrm{S} / \mathrm{L}$ interface). This depends on freezing temperature range $(\Delta T)$ and growth rate $(R)$. When $G / R$ ratio is more than that of $\Delta T / D_{L}$, it causes for planer mode of solidification. $D_{L}$ represents the solute diffusion coefficient in liquid. If $\mathrm{G} / \mathrm{R}$ ratio is less than that of $\Delta T / \mathrm{D}_{\mathrm{L}}$, the cellular, dendritic and equated type solidification will occur. During welding, weld thermal cycle shows variation in temperature at any particular location in and around the fusion zone as a function of welding time. As the plasma arc heat source approaches close to the location of interest first temperature increases heating regime followed by gradual decrease in temperature cooling regime. During weld thermal cycle, the base metal adjacent to the fusion zone experiences a range of peak temperature that are between liquidus and solidus temperature of the alloy. Since non-equilibrium conditions occur during weld thermal cycle, the microstructure in this region is susceptible to partial melting and termed as partially melted zone. The HAZ encounters a lower temperature range than the weld metal because of this it contains a mixture of acicular $\alpha$, primary $\alpha$ along with martensitic $\alpha$ prime. This is clearly observed from HAZ region. Since the weld metal meets higher temperature range, it is almost with full of martensite $\alpha$ prime phase.

\section{Results and Discussion}

A nonlinear transient heat transfer analysis has been carried out using ANSYS Finite element package. The Dhinakaran's model is used to reflect the thermal behavior of PAW heat sources. The temperature distribution predicted by the heat transfer analysis is given as load to carry out structural analysis. The structural analysis carried out with the Anand constitutive material model.

Figure 9 (a) - (d) shows the temperature distribution during plasma arc welding of Ti-6Al-4V alloy sheet of $2 \mathrm{~mm}$ thickness. After initiation of the plasma arc, the temperature reaches to $3661 \mathrm{~K}$ from initial temperature within the time interval to 1.2 seconds. The reason for noticing low temperature may be due to the fact that there is enough area ahead of the heat source which enhances the heat transfer. When the plasma arc travels about $9.5 \mathrm{sec}$ the temperature reaches to $3863 \mathrm{~K}$ and a quasi-steady state is observed Figure 9 (b). The peak temperature is seen as $3863 \mathrm{~K}$ during the welding process at all the heat source location after achieving the quasi steady state condition. Cooling of weldment takes place as soon as the torch moves ahead at any position. The temperature is observed to be high when torch reaches almost end of the plate.

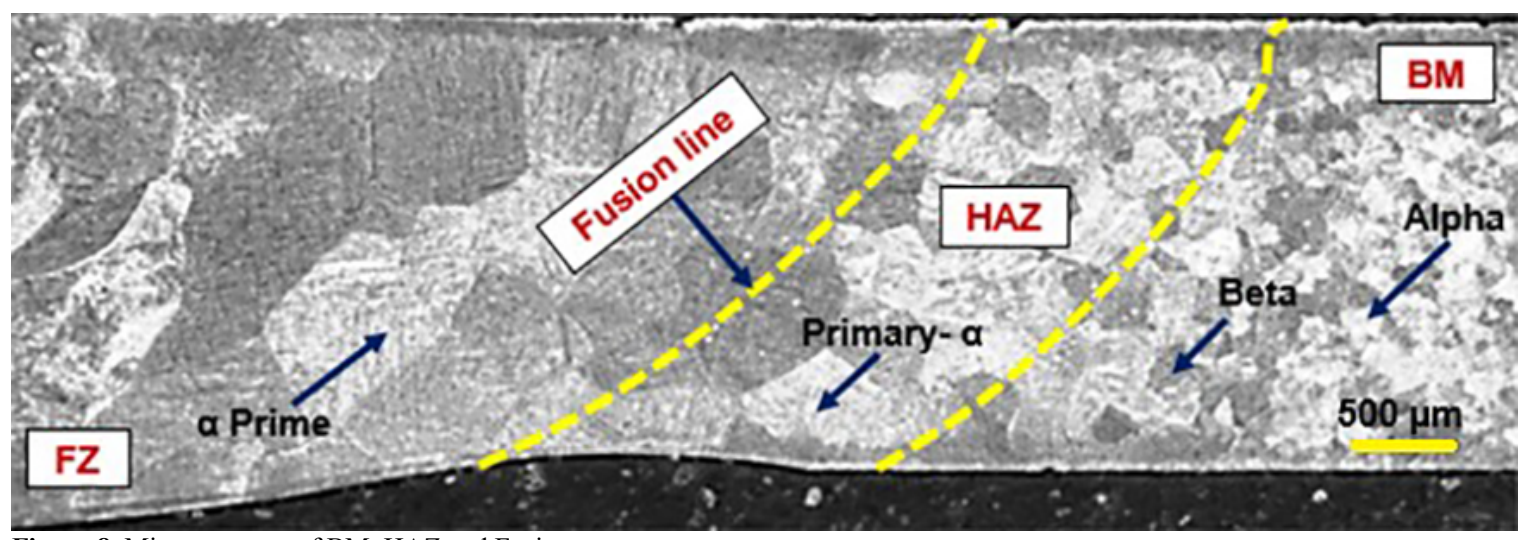

Figure 8. Microstructure of BM, HAZ and Fusion zone. 

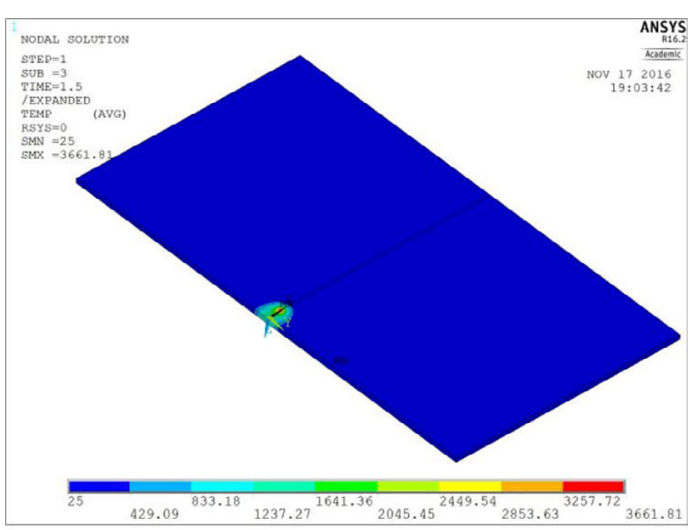

(a)

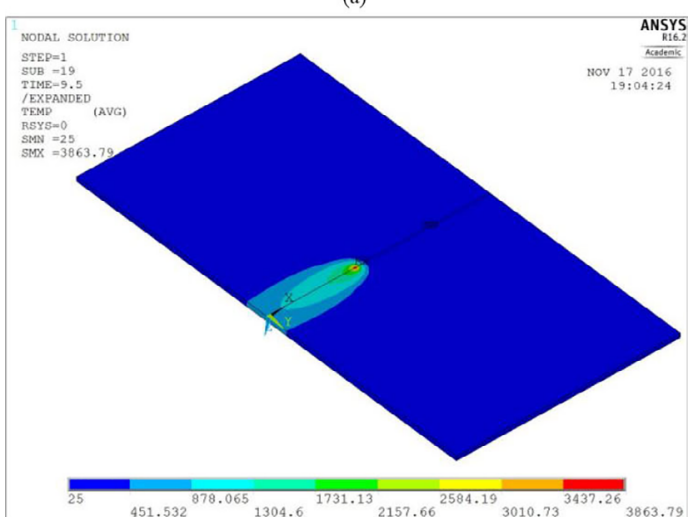

(b)
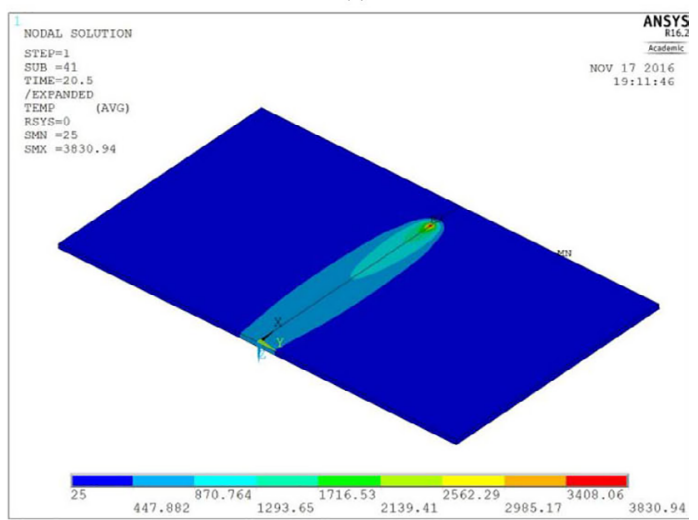

(c)

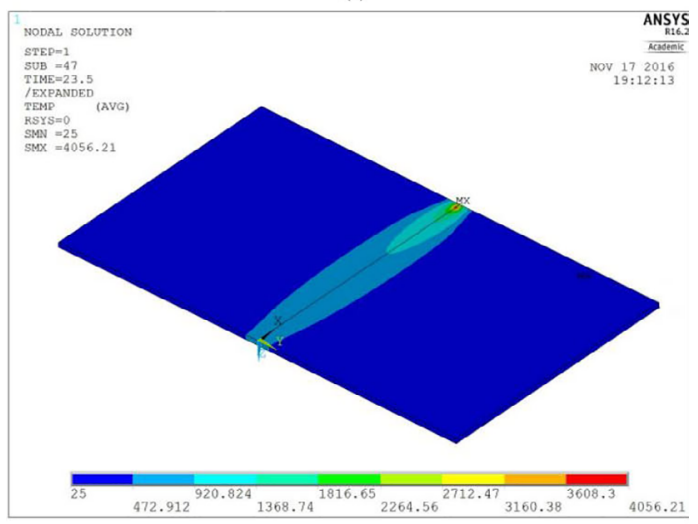

(d)

Figure 9. Temperature distribution during welding process for four different time steps $1.5 \mathrm{~s}$ (b) $9.5 \mathrm{~s}$ (c) $12 \mathrm{~s}$ and (d) $23.5 \mathrm{~s}$.
The area normal ahead of the torch position is very low because of which the heat transfer rate is reduced which intern rises the temperature. This is observed from the Figure 9 (d).

Figure 10 shows the temperature history at different locations along the transverse direction of the plate when the plasma torch is standing in the middle of the plate. At the weld interface $(x=0 \mathrm{~mm})$, the peak temperature is observed to be $3863 \mathrm{~K}$. The temperature goes on reducing when moved away from the torch position along the transverse direction and it reduces at any location when time increases.

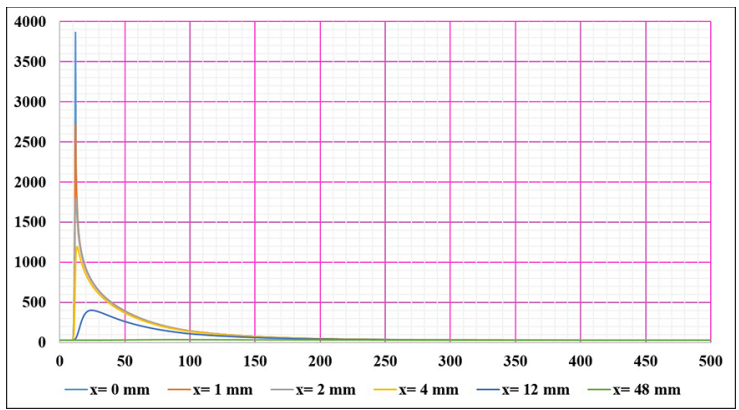

Figure 10. Temperature history at different locations when plasma torch is middle of the plate.

Residual stress distribution induced due to differential heating is shown in the Figure 11. At the weld interface, high thermal gradient leads to thermal expansion and this expansion is restricted by the surrounding material because of which contraction is experienced. Hence, tensile stress is noticed at the weld zone. These tensile stresses progressively decrease in the transverse direction away from the weld centerline and become compressive towards the edge of the plate. The maximum tensile stress in the transverse direction is noticed from the Figure 11 as $443 \mathrm{MPa}$ and compressive stress is observed to be $180 \mathrm{MPa}$. Hence, tensile stresses are observed to be developed at the weld zone. The magnitude of this tensile stress is maximum at the weld center line and then on decreases gradually in the transverse direction. Towards the edges of the plate the stress becomes compressive in nature.

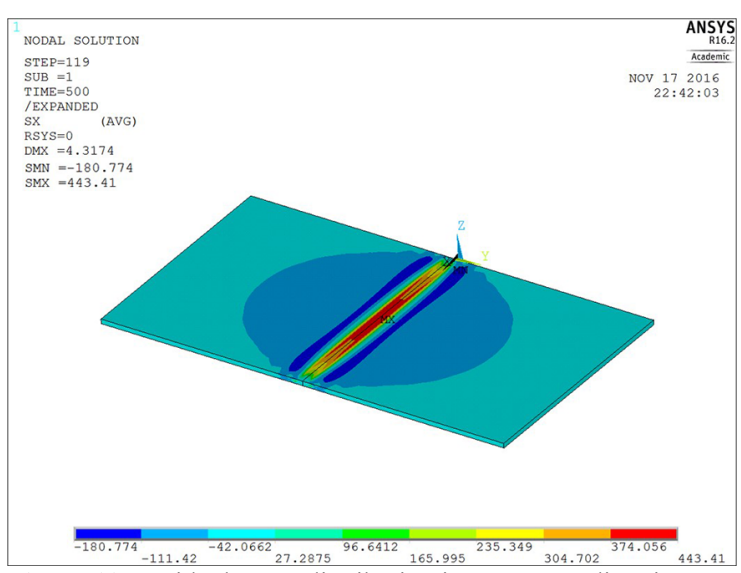

Figure 11. Residual stress distribution in transverse direction. 
The maximum tensile stress in the transverse direction is noticed from the Figure 12 to be $443 \mathrm{MPa}$ and compressive stress is observed to be $180 \mathrm{MPa}$.

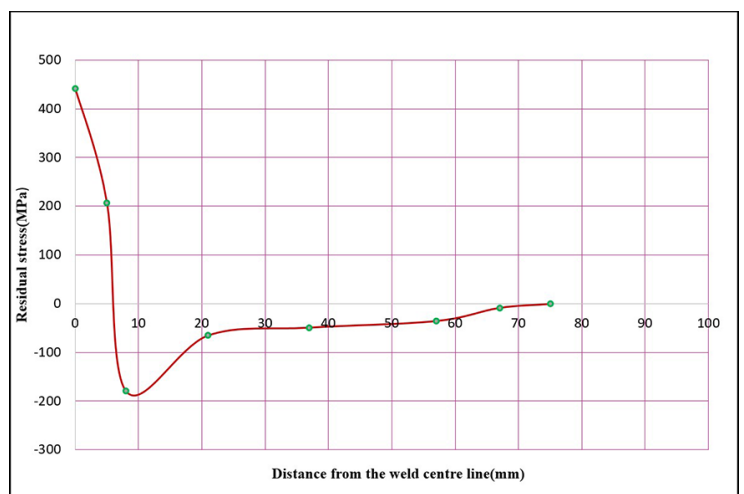

Figure 12. Residual stress distribution in transverse direction.

Figure 13 represents the residual stress distribution in the direction of welding. It is observed from the figure that the residual stress starts to increase when plasma torch is ignited and reaches a maximum value at the point where torch reaches centre position of the plate. The stress value starts to decrease gradually when torch moves away from centre of the plate along the direction of welding.

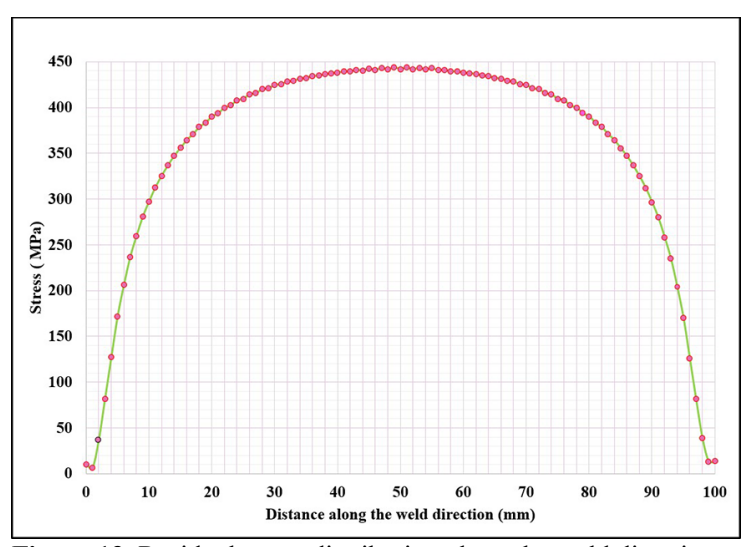

Figure 13. Residual stress distribution along the weld direction.

Figure 14 shows the angular distortion of the top surface predicted from the simulation. The angular distortion is defined as the angular displacement in relation to the $x$ axis. The value is observed to be $4.92 \mathrm{~mm}$ at the edge of the weld and zero at the weldment. The distortion gradually increases from the weld centerline to the edge of the weld. This type of distraction generally occurs.

Figure 15 shows the comparison of predicted residual stress across the butt weld joint from the numerical simulation, XRD and Hole Drilling Method (HDM) measurement. The residual stress is observed to be tensile up to $8 \mathrm{~mm}$ from the weld centre line in the transverse direction and then transition from tensile stress to compressive stress is taking place.

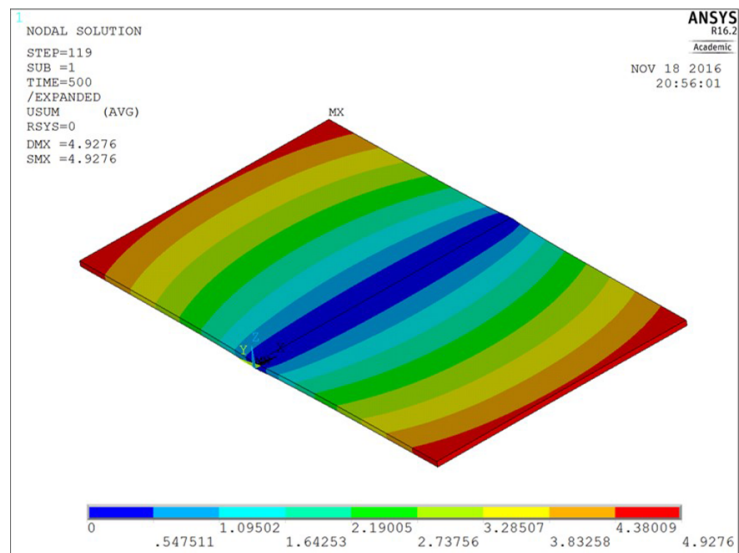

Figure 14. Angular distortion.

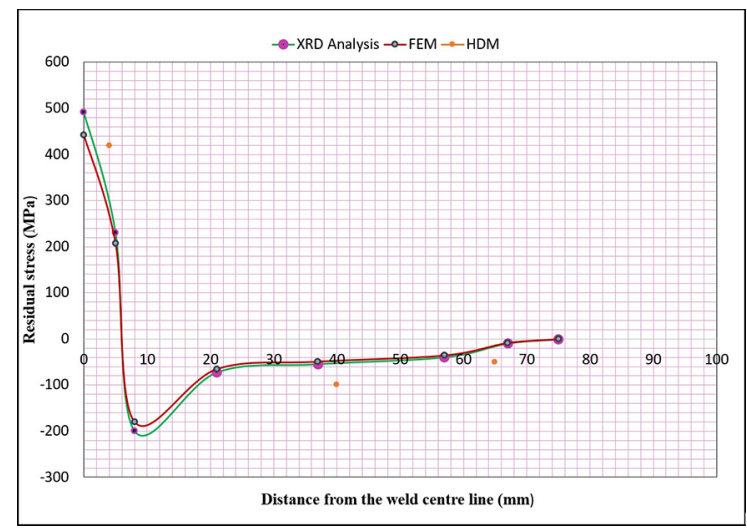

Figure 15. Comparison of transverse residual stress.

The maximum tensile stress is measured as $490 \mathrm{MPa}$ and predicted as $460 \mathrm{MPa}$ at the weld centre line. The reason for having tensile stress closer to fusion line is due to the expansion of metal. The region further away from weld centre line is in a compressive state because the expansion of these region is restrained by the surrounding cold metal. The measured stress value using HDM shows some difference in both experimental and simulated values and while also confirming that tensile stress are produced near the fusion zone and compressive stresses are produced away from the fusion zone.

\section{Conclusion}

This research work used finite element method to evaluate residual stress in butt welded joints. A new heat source model namely Dhinakaran's model has been used to simulate the temperature field through heat transfer analysis and Anand material model to carry out the structural analysis simulation using temperature load and mechanical boundary condition. Additionally, the HDM measurement results and XRD measurements results are used to validate the predicted residual stress from finite element simulation. Based on the results in this research work, the following conclusions are drawn. 
Residual stress predicted by finite element simulation shows good agreement with measurement of XRD experimental data. The temperature field predicted by Dhinakaran's model correctly yield input to structural model for the prediction of residual stress.

The computed residual stresses are in qualitatively good agreement with the experimental results.

A large tensile stress occurs near the weld zone in longitudinal direction up to a distance of $8 \mathrm{~mm}$ from the weld center line and compressive stress is observed away from weld bead.

HDM measurement however confirms the presence of tensile residual stress near the weld center line and the presence of compressive stress away from the weld center line.

The angle of distortion predicted by the simulation shows good agreement with the angle measured with experimental data and the maximum magnitude of the angular distortion both the side from the weld centerline seems to be almost same and it is known that the angular deformation developed is well balanced in both the side.

\section{References}

1. Boyer R, Coolings EW, Welsch G. Material Properties Handbook: Titanium Alloys. Ohio, USA: ASM International; 2007.

2. Donachie Junior MJ. Titanium: A Technical Guide. $2^{\text {nd }}$ ed. Ohio, USA: ASM International; 2000

3. Leyens C, Manfred P. Titanium and Titanium Alloys: Fundamentals and Applications. Weinheim, Germany: Wiley-VCH Verlag GmbH \& Co.; 2003.

4. Langford G. Plasma arc welding for large titanium aerospace structures. SAE Technical Paper. 1966;660646. DOI: https:// doi.org/10.4271/660646

5. Martikainen JK, Moisio TJI. Investigation of the effect of welding parameters on weld quality of plasma arc keyhole welding of structural steels. Welding Research Supplement. 1993;329S-340S

6. Masubuchi K. Analysis of welded structures: residual stresses, distortion, and their consequences. $1^{\text {st }}$ ed. Oxford: Pergamon; 2013.

7. Tseng KH, Huang JM. Arc efficiency assisted finite element model for predicting residual stress of TIG welded sheet. Journal of Computers. 2013;8(9):2183-89.

8. Abdelaziz SL, Ozudogru TY. Non-uniform thermal strains and stresses in energy piles. Journal of Environmental Geotechnics. 2016;3(4):237-252.

9. Gutiérrez PH, Rodríguez FC, Mondragón JJR, Dávila JLA, Mata MPG, Chavez CAG. Thermo-mechanic and microstructural analysis of an underwater welding joint. Soldagem e Inspeção. 2016;21(2):156-164.

10. Yaghi AH, Hyde TH, Becker AA, Sun W. Finite element simulation of welding and residual stresses in a P91 steel pipe incorporating solid-state phase transformation and post-weld heat treatment. The Journal of Strain Analysis for Engineering Design. 2008;43(5):275-293.
11. Ijiri M, Yoshimura T. Sustainability of compressive residual stress on the processing time of water jet peening using ultrasonic power. Heliyon. 2018;4(8):e00747.

12. Chuan L, Jianxun Z, Jing N. Numerical and experimental analysis of residual stresses in full-penetration laser beam welding of Ti6Al4V alloy. Rare Metal Materials and Engineering. 2009;38(8):1317-1320.

13. Stamenković D, Vasović I. Finite element analysis of residual stress in butt welding two similar plates. Scientific Technical Review. 2009;59(1):57-60.

14. Liu W, Ma J, Kong F, Liu S, Kovacevic R. Numerical modeling and experimental verification of residual stress in autogenous laser welding of high-strength steel. Lasers in Manufacturing and Materials Processing. 2015;2(1):24-42.

15. Mi G, Li C, Gao Z, Zhao D, Niu J. Finite element analysis of welding residual stress of aluminum plates under different butt joint parameters. Engineering Review. 2014;34(3):161-166.

16. Xiao B, Li K, Wang Q, Rong Y. Numerical simulation and experimental validation of residual stresses in water-quenched aluminum alloy castings. Journal of Materials Engineering and Performance. 2011;20(9):1648-1657.

17. Zubairuddin M, Shaju KA, Mahadevan S, Vasudevan M, Chaudhari V, Suri VK. Experimental and finite element analysis of residual stress and distortion in GTA welding of modified 9Cr-1Mo steel. Journal of Mechanical Science and Technology. 2014;28(12):5095-5105.

18. Zhu XK, Chao YJ. Numerical simulation of transient temperature and residual stresses in friction stir welding of 304L stainless steel. Journal of Materials Processing Technology. 2004;146(2):263-272.

19. Dhinakaran V, Shanmugam NS, Sankaranarayanasamy K, Rahul R. Analytical and numerical investigations of weld bead shape in plasma arc welding of thin Ti-6Al-4V sheets. Simulation. 2017;93(12):1123-1138.

20. Dhinakaran V, Shanmugam NS, Sankaranarayanasamy K. Some studies on temperature field during plasma arc welding of thin titanium alloy sheets using parabolic Gaussian heat source model. Proceedings of the Institution of Mechanical Engineers, Part C: Journal of Mechanical Engineering Science. 2017;231(4):695711.

21. Patil AS, Ingle SV, More YS, Nathe MS. Machining challenges in Ti-6Al-4V.-A Review. International Journal of Innovations in Engineering and Technology (IJIET). 2015;5(4):6-23.

22. Dhinakaran V, Shanmugam NS, Sankaranarayanasamy K. Experimental investigation and numerical simulation of weld bead geometry and temperature distribution during plasma arc welding of thin Ti-6Al-4V sheets. The Journal of Strain Analysis for Engineering Design. 2017;52(1):30-44.

23. Šarga P, Menda F. Comparison of ring-core method and holedrilling method used for determining residual stresses. American Journal of Mechanical Engineering. 2013;1(7):335-338.

24. Von Mirbach D. Hole-drilling method for residual stress measurement-consideration of elastic-plastic material properties. Materials Science Forum. 2013;768-769:174-181. 
25. ASTM - American Society for Testing and Materials. E-83701 - Test method for determining residual stresses by the hole-drilling strain-gage method. West Conshohocken, USA: ASTM International; 2001.

26. Vishay Precision Group. Micro-Measurements (MM). Measurement of residual stresses by the hole drilling* strain gage method. Tech Note TN 503. 2007;1-16.

27. Paranjpe SK. Measurement of residual stress in materials using neutrons. In: Proceedings of a Technical Meeting Held in Vienna; 2003 oct 13-17. Vienna, Austria: International Atomic Energy Agency - IAEA; 2005. p. 1-92.

28. Dhinakaran V, Shanmugam NS, Sankaranarayanasamy K. Numerical prediction of weld bead geometry in plasma arc welding of titanium sheets using COMSOL. In: Proceedings of the 2014 COMSOL Conference in Bangalore; 2014 nov 13-14. Bangalore, India: COMSOL; 2014. p. 13-14.

29. Shanmugam NS, Buvanashekaran G, Sankaranarayanasamy K, Kumar SR. A transient finite element simulation of the temperature and bead profiles of T-joint laser welds. Materials and Design. 2010;31(9):4528-4542.

30. Shanmugam NS, Buvanashekaran G, Sankaranarayanasamy K. Some studies on weld bead geometries for laser spot welding process using finite element analysis. Materials and Design. 2012;34:412-426.

31. Lee Y, Basaran C. A creep model for solder alloys. Journal of Electronic Packaging. 2011;133(4):044501.

32. Qin XL, Michaleris P. Elasto-visco-plastic analysis of welding residual stress. Science and Technology of Welding and Joining. 2009;14(7):606-615.

33. Castellanos J, Rieiro I, Carsí M, Ruano OA. Analysis of Garofalo equation parameters for an ultrahigh carbon steel. Journal of Materials Science. 2010;45(20):5522-5527.

34. Vemanaboina H, Edison G, Akella S, Buddu RK. Effect of residual stresses of GTA welding for dissimilar materials. Materials Research. 2018;21(4):e20171053. 